The FASEB Journal express article 10.1096/fj.00-0509fje. Published online January 5, 2001.

\title{
Protection by nitric oxide against liver inflammatory injury in animals carrying a nitric oxide synthase- 2 transgene
}

Marina Mojena, ${ }^{*}$ Sonsoles Hortelano, ${ }^{\dagger}$ Antonio Castrillo, ${ }^{\dagger}$ María J. M. Díaz-Guerra, ${ }^{\ddagger}$ María J. García-Barchino, ${ }^{\S}$ Guillermo T. Sáez, ${ }^{\S}$ and Lisardo Boscá ${ }^{\dagger}$

*Centro de Investigación Básica de España (CIBE), Merck Sharp \& Dohme, Madrid; ${ }^{\dagger}$ Instituto de Bioquímica, Centro Mixto CSIC-UCM, Facultad de Farmacia, Universidad Complutense, 28040 Madrid; Departamento de Bioquímica, Facultad de Medicina, Campus Universitario, 02071 Albacete; and ${ }^{\S}$ Departamento de Bioquímica y Biología Molecular, Facultad de Medicina, Universitat de Valencia, Valencia, Spain

Corresponding author: Lisardo Boscá, Instituto de Bioquímica, Facultad de Farmacia, 28040 Madrid, Spain. E-mail: boscal@eucmax.sim.ucm.es

\begin{abstract}
The effect of pre-existent hepatic NO synthesis on liver injury induced by lipopolysaccharide was studied in animals carrying a nitric oxide synthase-2 (NOS-2) transgene under the control of the phosphoenolpyruvate carboxykinase (PEPCK) promoter. These animals expressed NOS-2 in liver cells under fasting conditions. Lipopolysaccharide-induced liver injury in D-galactosamineconditioned mice, which enhanced notably the effect of the endotoxin on the liver, was impaired in animals expressing NOS-2. This protection against inflammatory liver damage was dependent on NO synthesis and was caused by an inhibition of nuclear factor $\kappa \mathrm{B}(\mathrm{NF}-\kappa \mathrm{B})$ activity and an impairment of the synthesis of the proinflammatory cytokines tumor necrosis factor $\alpha$ and interleukin $1 \beta$. These data indicate that intrahepatic synthesis of NO protects liver by inhibiting the release of cascades of proinflammatory mediators and suggest a beneficial role for local delivery of $\mathrm{NO}$ in the control of liver injury.
\end{abstract}

Key Words: liver cells • lipopolysaccharide

\footnotetext{
T $\mathrm{n}$ the course of sepsis, various cell types in the infected organism contribute to the release of cytokines [among them tumor necrosis factor $\alpha$ (TNF- $\alpha$ ), interleukin $1 \beta$ (IL-1 $\beta$ ), and interferon $\gamma$ (IFN- $\gamma$ )] and chemokines, which recruit and activate additional cells of the immune system. These proinflammatory mediators promote the synthesis of odd molecules that participate in host defense, such as reactive-oxygen species, NO, and bioactive lipids (mainly prostaglandins, leukotrienes, and thromboxanes) (1-3). Current views about the pharmacological control of inflammatory onset have focused on the neutralization or inhibition of release of proinflammatory cytokines, as well as on the regulation of NO synthesis, which exerts an important pathophysiological action that induces refractory hypotension and severe damage in the renal and cardiovascular systems (4-9).
} 
The response of liver to pro-inflammatory stimuli has been well established and, in addition to specialized cells (e.g., Kupffer cells), hepatocytes respond to most of these factors (10-14). Moreover, the liver is an important contributor to the synthesis of systemic mediators of the inflammatory cascade during sepsis, such as acute-phase proteins and pro-inflammatory cytokines $(15,16)$. One key component in the triggering of the inflammatory response is the activation of nuclear factor $\kappa \mathrm{B}(\mathrm{NF}-\mathrm{\kappa B})$, a transcription factor that integrates the signaling elicited by various cell stresses and is required for the expression of most genes involved in host defense, among them the NOS-2 gene (4, 17-19). Indeed, the important role played by NF- $\mathrm{B}$ activation in liver inflammation has been confirmed in animals carrying a degradation-resistant $\mathrm{I} \kappa \mathrm{B} \alpha$ transgene under the control of a liver-specific promoter (20) and in cultured hepatocytes transduced with adenovirus carrying an I $\kappa \mathrm{B} \alpha$ gene that impairs NOS-2 expression (21).

In liver cells, expression of NOS-2 leads to the synthesis of large amounts of NO, and genetic and pharmacological data suggest that this molecule exerts a dual role in the course of inflammation: exogenous addition of NO impairs the release of inflammatory mediators (22-25) and protects against apoptotic death by inhibiting various caspases via nitrosylation of key cysteine residues (26-28). Synthesis of NO after expression of NOS-2 is responsible for an important part of the damage occurring during sepsis (29-31). Moreover, the exacerbated inflammatory responses in animals resuscitated after hemorrhagic shock, which promotes severe damage in liver and lungs, were markedly attenuated in animals lacking NOS-2 or treated with NOS-2 inhibitors, due to less NF- $\mathrm{KB}$ activation and synthesis of proinflammatory mediators (32). However, liver injury in the course of mild endotoxemia even increased when NOS-2 activity was inhibited (33). In addition to these effects, NO has been identified as a molecule required for liver regeneration after partial hepatectomy, as deduced by the impairment of hepatocyte growth in animals with inhibited NOS or lacking the NOS-2 gene $(11,34)$.

Keeping in mind these previous data, we developed an experimental animal model to investigate the potential contribution of NO to the modulation of inflammatory liver injury, in which NO was endogenously produced in the hepatocytes by expression of an NOS-2 transgene under the control of the liver-specific PEPCK promoter. These animals expressed NOS-2 after fasting, in a process that was independent from proinflammatory stimulation. Moreover, the PEPCK promoter was activated in the postnatal period, avoiding interference in the course of animal development. Using this approach, we have analyzed the pathophysiological effect of sustained expression of NOS-2 in hepatocytes during fasting, as well as the modulation exerted by this local synthesis of NO on the progression of several models of inflammatory liver injury, taking advantage of the enhancement of liver toxicity induced by D-galactosamine (D-GalN) administration $(35,36)$. Our data show that preexistent synthesis of NO in the hepatocyte exerts an important protection against lipopolysaccharide (LPS)-dependent injury in D-GalN preconditioned mice.

\section{MATERIAL AND METHODS}

\section{Chemicals}

LPS (from Salmonella enterica serovar Typhimurium), L-N(6)-(1-iminoethyl)lysine (L-NIL), TNF- $\alpha$, and D-GalN were obtained from Sigma (St. Louis, Mo.). $N$-(3-Aminomethylbenzyl)acetamidine, 
1400W, was a gift from R. Knowles. Antibodies were from Santa Cruz Laboratories (Santa Cruz, Calif.) and PharMingen (Heidelberg, Germany). Terminal deoxynucleotidyltransferase-mediated dUTP-fluorescein nick-end-labeling (TUNEL) reagents were from Roche (Mannheim, Germany). Cytokine assay Biotrak kits, oligonucleotides, and restriction enzymes were from Amersham (Bucks, United Kingdom). Electrophoresis equipment and reagents were from Bio-Rad (Hercules, Calif.).

\section{Construction of the pPEPCK/NOS-2 gene and generation of transgenic animals}

The chimeric gene contained the $X b a \mathrm{I}-B g l \mathrm{II}$ fragment of the rat PEPCK promoter (nucleotides 450 to +73 ) linked to the initial 5' sequence of the human insulin gene in which the transcription start site was deleted (BgII-NcoI fragment) (37). To this sequence, the full coding sequences of the murine NOS-2 cDNA $(3.93 \mathrm{~kb})$ and the 3 ' end of the insulin gene (NcoI-HindIII fragment) were linked and cloned into a pTZ18R (USB) plasmid, following the strategy described previously $(37,38)$. A $6.2 \mathrm{~kb} \mathrm{KpnI-HindIII} \mathrm{fragment} \mathrm{containing} \mathrm{the} \mathrm{chimeric} \mathrm{gene} \mathrm{(Fig.} \mathrm{1A)} \mathrm{was}$ microinjected into fertilized eggs from strain C57B16/SJL mice as previously described (37). The presence of the transgene was determined in 3-week-old mice by Southern blotting of tail DNA that had been digested with EcoRI and HindIII, leading to the excision of a $2.9 \mathrm{~kb}$ fragment of the transgene (Fig. 1B). Blots were hybridized with the $2.8 \mathrm{~kb} E c o$ RI-SSpI fragment corresponding to nucleotides +1124 to +3934 of the murine NOS-2 cDNA. The probe was radiolabeled with $\left[\alpha-{ }^{32} \mathrm{P}\right] \mathrm{dCTP}(3,000 \mathrm{Ci} / \mathrm{mmol})$ by random oligopriming (Amersham). Wildtype (Wt) and transgenic ( $\mathrm{Tg}$ ) mice were fed ad libitum with a standard diet (Panlab, Barcelona, Spain) and kept under a light-dark cycle of alternating $12 \mathrm{~h}$ periods (lights on at 8 a.m.). Starvation was initiated at 10 a.m. and experiments were started the next day between 8 a.m. and 10 a.m.

Administration of $1400 \mathrm{~W}, \mathrm{~L}-\mathrm{NIL}, \mathrm{D}-\mathrm{GalN}$, LPS, and TNF- $\alpha$ was done intraperitoneally (i.p.). Animals were cared for in agreement with the institutional animal care instructions. Sera were obtained by cardiac puncture or through the tail vein.

\section{Measurement of metabolites}

Livers were quickly removed and frozen in liquid $\mathrm{N}_{2}$. Lipid peroxidation was quantified by measuring malondialdehyde (MDA) products, using the thiobarbituric acid assay (39). GSH and GSSG were measured as previously described (40). The amount of 8-OHdG was determined by HPLC after isolation and hydrolysis of DNA (41). Serum nitrite plus nitrate was measured using a chemiluminescence method, following the recommendations of the manufacturer (NO analyzer; Sievers, Boulder, Colo.).

\section{Preparation of cytosolic and nuclear protein extracts}

Samples of liver tissue (100-200 mg) were homogenized in 4 volumes of ice-cold buffer A (10 mM HEPES [pH 7.9], $1 \mathrm{mM}$ EDTA, $1 \mathrm{mM}$ EGTA, $10 \mathrm{mM} \mathrm{KCl,} 1 \mathrm{mM}$ dithiothreitol, $0.5 \mathrm{mM}$ PMSF, $2 \mu \mathrm{g} / \mathrm{ml}$ tosyl-lysyl-chloromethane, $40 \mu \mathrm{g} / \mathrm{ml}$ aprotinin, $4 \mu \mathrm{g} / \mathrm{ml}$ leupeptin, $5 \mathrm{mM} \mathrm{NaF}, 1$ $\mathrm{mM} \mathrm{NaVO}_{4}, 10 \mathrm{mM} \mathrm{Na}_{2} \mathrm{MoO}_{4}$, and $0.5 \%$ [vol:vol] Nonidet P-40). After centrifugation at 8,000 $\times g$ for $15 \mathrm{~min}$, the supernatants were stored at $-80^{\circ} \mathrm{C}$ (soluble extracts), and the pellets were 
resuspended in $200 \mu \mathrm{l}$ of buffer A supplemented with $20 \%$ (vol:vol) glycerol and $0.4 \mathrm{M} \mathrm{KCl}$ and vortexed for $30 \mathrm{~min}$ at $4^{\circ} \mathrm{C}$. The nuclear suspension was centrifuged in an Eppendorf centrifuge, and the supernatant was stored at $-80^{\circ} \mathrm{C}$ (nuclear extract).

\section{Measurement of enzyme activities}

The activities of the hepatic markers alanine aminotransferase (ALT), aspartate aminotransferase (AST), and $\gamma$-glutamyl transferase $(\gamma-\mathrm{GT})$ were measured at $30^{\circ} \mathrm{C}$, using commercial kits for diagnosis. Superoxide dismutase (SOD) was measured by the production of superoxide during the conversion of xanthine to uric acid by xanthine oxidase and inhibition of cytochrome $c$ reduction (42). Catalase was measured after the decomposition of $\mathrm{H}_{2} \mathrm{O}_{2}$ at $240 \mathrm{~nm}$. Glutathione peroxidase (GPX) was measured by recording the oxidation of GSH by $\mathrm{H}_{2} \mathrm{O}_{2}$. The activity of caspase $3 / 7$ was measured using as substrate $N$-acetyl-DEVD-7-amino-4-methylcoumarin and in the presence of 1 $\mathrm{mM}$ dithiothreitol, by following the instructions of the supplier (PharMingen, Heidelberg, Germany). The corresponding peptide aldehyde was used to inhibit the caspase activity in vitro and to ensure the specificity of the reaction. The linearity of the caspase assays was determined over a 30-min reaction period.

\section{Analysis of gene expression by Northern blot}

Total RNA was extracted from $50 \mathrm{mg}$ of liver tissue by the guanidinium thiocyanate method (18). After electrophoresis in a $0.9 \%$ agarose gel containing $2 \%$ formaldehyde, the RNA was transferred to a Nytran membrane (NY 13-N; Schleicher \& Schuell, Dassel, Germany), and the level of IאB $\alpha$ mRNA was determined using the full cDNA as a probe, after labeling with the Rediprime kit (Amersham). The membranes were exposed to Hyperfilm X-ray films (Amersham), and the intensity of the bands was measured by laser densitometry (Molecular Dynamics). The lane charge was normalized by hybridization with a ribosomal $18 \mathrm{~S}$ probe.

\section{Western blot analysis}

The relative amounts of NOS-2, I $\mathrm{KB} \alpha$, and procaspase 3 were determined in soluble extracts. The levels of p65 were determined in nuclear extracts. Equal amounts of protein were sizefractionated by SDS-10\% PAGE, transferred to a PVDF membrane (Amersham), and, after blocking with 5\% nonfat dry milk, incubated with the corresponding antibodies (1:1000) from Santa Cruz Laboratories. The blot was revealed after incubation with horseradish peroxidaseconjugated IgG (1:2000) and after following the ECL protocol (Amersham), as recommended by the manufacturer. Different exposition times were performed for each blot to ensure the linearity of the band intensities. Densitometric analysis of the bands was carried out using a laser densitometer (Molecular Dynamics, Sunnyvale Calif.).

\section{Electrophoretic mobility shift assays (EMSAs)}

The oligonucleotide corresponding to the proximal $\mathrm{kB}$ motif of the murine iNOS promoter (43) 5'CCAACTGGGGACTCTCCCTTTGGGAACA-3' (50 ng) was annealed with the complementary sequence and end-labeled with Klenow enzyme in the presence of $50 \mu \mathrm{Ci}$ of $\left[\alpha-{ }^{32} \mathrm{P}\right] \mathrm{dCTP}$ and the other unlabeled dNTP in a final volume of $50 \mu 1$. The oligonucleotide was precipitated with ethanol 
and extracted with phenol/chloroform (44). Binding assays of nuclear extracts were carried out with $5 \times 10^{4} \mathrm{dpm}$ of the DNA probe as follows: nuclear protein extract $(5 \mu \mathrm{g})$ was incubated for $30 \mathrm{~min}$ at $4^{\circ} \mathrm{C}$ with the DNA and $1-\mu \mathrm{g} / \mathrm{ml}$ poly $(\mathrm{dI} \cdot \mathrm{dC}), 5 \%$ glycerol, $1 \mathrm{mM}$ EDTA, $100 \mathrm{mM} \mathrm{KCl}, 5 \mathrm{mM}$ $\mathrm{MgCl}_{2}, 1 \mathrm{mM}$ dithiothreitol, and $10 \mathrm{mM}$ Tris-HCl (pH 7.8), in a final volume of $20 \mu \mathrm{l}$. Samples were applied to a $6 \%$ polyacrylamide gel which had been previously electrophoresed for $30 \mathrm{~min}$ at $100 \mathrm{~V}$. Gels were run at $0.8 \mathrm{~V} / \mathrm{cm}^{2}$ in $45 \mathrm{mM}$ Tris-borate, followed by transfer to 3MM Whatman filter paper, drying under vacuum at $80^{\circ} \mathrm{C}$, and quantification of the band intensities in an autoradiograph (Fuji Bas 1000). Specificity of the protein-DNA interaction was ensured by serial dilutions of the binding assay with an excess of unlabeled probe. Supershift assays were carried out after incubation of the nuclear extracts at $4^{\circ} \mathrm{C}$ for $30 \mathrm{~min}$ with $2 \mu \mathrm{g}$ of the indicated Abs.

\section{Cytokine assay}

The serum levels of TNF- $\alpha$ and IL-1 $\beta$ were measured per duplicate sample, using commercial kits (Biotrak; Amersham).

\section{Cytochemistry and TUNEL assays}

Liver sections were fixed on $2 \%$ paraformaldehyde in phosphate buffer and embedded into paraffin. After deparaffinization, sections of $8 \mu \mathrm{m}$ in thickness were stained with hematoxylin and eosin, or they were treated with the reagents of the TUNEL kit (Roche) to evaluate apoptosis.

\section{DNA extraction and analysis}

Internucleosomal DNA fragmentation was analyzed by agarose gel electrophoresis (45). Samples of liver (200 mg each) were Dounce homogenized with $1.5 \mathrm{ml}$ of $10 \mathrm{mM}$ EDTA, $0.25 \%$ Triton X100, and $20 \mathrm{mM}$ Tris- $\mathrm{HCl}(\mathrm{pH} 8.0)\left(15 \mathrm{~min}\right.$ at $\left.4^{\circ} \mathrm{C}\right)$. The DNA was precipitated with $70 \%$ ethanol plus $2 \mathrm{mM} \mathrm{MgSO}_{4}$ and treated for $4 \mathrm{~h}$ at $55^{\circ} \mathrm{C}$ with $0.5 \mathrm{mg} / \mathrm{ml}$ of proteinase $\mathrm{K}$. After two extractions with phenol/chloroform, the DNA was analyzed in a $2 \%$ agarose gel and stained with $0.5 \mu \mathrm{g} / \mathrm{ml}$ of ethidium bromide.

\section{Statistical analysis}

The data described are the means \pm SD of the indicated number of experiments. Statistical significance was estimated with Student's $t$-test for unpaired observations. A $P$ value of less than 0.05 was considered significant. In studies using Western blot analysis, linear correlations between increasing amounts of protein and signal intensity were observed.

\section{RESULTS}

\section{Expression of the NOS-2 transgene under fasting conditions}

The presence of the NOS-2 transgene was determined by Southern blotting of tail DNA (Fig. 1B), the expression of this enzyme was assessed after starvation for both 24 and $48 \mathrm{~h}$, and analysis of NOS-2 in liver cells was accomplished by Western blotting. As Figure 1C shows, the protein was undetectable in fed animals, but a band of the expected size of NOS-2 was observed in animals 
starved for $24 \mathrm{~h}$; however, prolonged starvation of up to $48 \mathrm{~h}$ did not result in higher levels of NOS2. To ensure that this enzyme was active in the animal, the serum levels of $\mathrm{NO}_{2}{ }^{-}$plus $\mathrm{NO}_{3}{ }^{-}$(NOx), as end products of NO biosynthesis, were measured in fed and starved conditions (Fig. 1D). The maximal levels of NOx were detected at $24 \mathrm{~h}$ and were inhibited after administration of the NOS-2 inhibitors 1400W (Fig. 1D) and L-NIL (not shown). Moreover, in vitro measurement of NOS-2 activity in liver extracts by the conversion of arginine into citrulline and inhibition by $1400 \mathrm{~W}$ confirmed the expression of a functional enzyme in $\mathrm{Tg}$ animals under fasting conditions (data not shown). The presence of NOS-2 in other tissues of mice that had fasted was determined by Western blot, and only moderate expression in kidney cells was observed [note that the blot was overexposed for liver (Fig. 1E)].

Because the sustained synthesis of NO in starved animals might influence liver physiology, we investigated the levels of metabolites sensitive to $\mathrm{NO}$ as well as those of enzymes involved in oxidative stress. As Figure 2 shows, the levels of GSH decreased notably in both Wt and Tg animals under fasting conditions, and this effect was paralleled by an increase in GSSG concentration (3.8fold with respect to the Wt group at $48 \mathrm{~h}$ ). The accumulation of $8-\mathrm{OHdG}$ increased significantly by $24 \mathrm{~h}$ of starvation in Tg animals with respect to the Wt (twofold), and an increase of MDA (2.1fold) was evidenced after $48 \mathrm{~h}$. Regarding enzymes involved in oxidative stress, moderate but significant changes were observed in the activities of catalase at $48 \mathrm{~h}$ of starvation (57\% increase) and SOD at $24 \mathrm{~h}(55 \%)$. The most significant change was observed in GPX, which increased 3.4fold in starved $\mathrm{Tg}$ animals when compared with the Wt (Fig. 2).

\section{Protection by endogenous NO against LPS/D-GalN toxicity}

To further investigate in Tg animals the role of fasting-dependent NO synthesis on liver function, we analyzed two models of lethal endotoxic injury: i.p. injection of a high dose of LPS (40 mg/ $\mathrm{kg}$ ), and i.p. administration of a low dose of LPS $(10 \mu \mathrm{g} / \mathrm{kg})$ or TNF- $\alpha(20 \mu \mathrm{g} / \mathrm{kg})$ in combination with D-GalN (800 mg/kg) and L-NIL (5 mg/kg), an inhibitor of NOS-2 activity. As Table 1 shows, the survival rates with high doses of LPS did not significantly differ between Wt and $\mathrm{Tg}$ animals, regardless of their nutritional status. However, in D-GalN-conditioned mice, a protective effect (ca. 75\%) was observed in Tg animals expressing NOS-2, after challenge with a low dose of LPS. When animals were treated with TNF- $\alpha$ and D-GalN, significant protection was still observed in the Tg group that had fasted, although this protection was less efficient than that after LPS/D-GalN administration (67\% of survival). It is interesting that when NOS-2 activity was inhibited with LNIL, the protective effect of endogenous NO was lost. These results suggest that impairment of proinflammatory cytokine synthesis by $\mathrm{NO}$ in liver is a likely mechanism mediating animal survival, as observed in other models of acute endotoxic liver injury $(46,47)$. To analyze the protection exerted by NO synthesis on LPS/D-GalN-dependent toxicity, the levels of the proinflammatory cytokines TNF- $\alpha$ and IL- $\beta$ were determined at $4 \mathrm{~h}$ after i.p. challenge. As Figure 3 shows, 3.6- and 6.5-fold reductions of TNF- $\alpha$ and IL-1 $\beta$ levels, respectively, were observed in starved Tg animals, an effect that was lost after treatment with the NOS-2 inhibitor L-NIL. This reduced inflammatory response was absent in fed animals. In parallel to determination of the serum levels of proinflammatory cytokines, the activities of hepatic lesion markers $\gamma$-GT, ALT, and AST were determined to evaluate the degree of hepatic injury. As Figure 4 shows, a remarkable reduction in the serum levels of ALT (76\%) and AST (65\%) was observed, in agreement with the decreased 
levels of proinflammatory cytokines. However, the release of $\gamma$-GT activity was proportionally higher than that of transaminases (55\% decrease).

\section{Impairment of NF- $\mathrm{kB}$ activity in Tg animals expressing NOS-2}

One of the potential mechanisms of protection against LPS/D-GalN injury is the inhibition of NF$\mathrm{\kappa B}$ activation due to the endogenous synthesis of NO. To investigate this possibility, liver extracts were prepared, and the activity of NF- $\mathrm{KB}$ in the nuclear protein fraction was evaluated by EMSA. As Figure 5A shows, an important decrease of NF- $\mathrm{KB}$ activity was observed in starved Tg animals treated with LPS/D-GalN. Analysis of the retained bands by supershift assays showed a dominant composition of p50-p65 complexes in the upper band and p50 homodimers in the lower band, respectively. The attenuated $\mathrm{NF}-\kappa \mathrm{B}$ activity in starved $\mathrm{Tg}$ mice was accompanied by the presence of

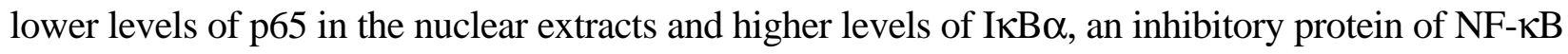
that retains the complex in the cytosol, in the corresponding soluble fraction $(18,48)$. This decreased NF- $\kappa B$ activity was accompanied by reduced levels of $\mathrm{I} \kappa \mathrm{B} \alpha \mathrm{mRNA}$, an early and sensitive NF-кB-regulated gene (Fig. 5B), reflecting an impaired inflammatory status.

Part of the cytotoxic effects due to LPS/D-GalN administration have been attributed to induction of liver apoptosis. To better evaluate the protection against apoptosis exerted by endogenous NO, liver extracts were prepared, and the levels of procaspase 3, the activity of caspase 3, and the nucleosomal fragmentation of DNA were determined. As Figure 6A shows, the levels of procaspase 3 were maintained in Tg animals that had fasted (up to $7 \mathrm{~h}$ after LPS/D-GalN challenge), whereas a significant decrease in procaspase 3 was observed in the corresponding Wt animals. The decrease in procaspase 3 was paralleled by the appearance of caspase- 3 activity. This activity was measured in the presence of $1 \mathrm{mM}$ dithiothreitol, which abrogates any possible inhibitory nitrosylation of the enzyme (49) (Fig. 6B), and by the occurrence of internucleosomal degradation of DNA when examined in agarose gels (Fig. 6C). Inhibition of NOS-2 activity with L-NIL suppressed the protective effects of NO synthesis in Tg animals. Moreover, TUNEL assays of liver sections obtained $7 \mathrm{~h}$ after LPS/D-GalN challenge showed an intense nuclear staining in starved Wt animals, together with a marked alteration in the tissue structure (deduced from hematoxylin and eosin staining), reflecting a certain degree of necrosis (Fig. 7). However, this response was absent in $\mathrm{Tg}$ animals that exhibited a normal tissue morphology, and, occasionally, the cells surrounding the centrilobular vein exhibited an increased fluorescence in the cytoplasm but not in the nucleus, suggesting certain apoptotic damage. It is interesting that treatment of animals with L-NIL suppressed the protective effect exerted by the endogenous synthesis of NO.

\section{DISCUSSION}

A study of the effects of NO in a particular tissue using an exogenous source of this molecule encompasses many undesirable side effects due to the yet unresolved difficulty of selective delivery in the organ, at least at NO concentrations similar to those released after NOS-2 expression. To overcome this problem in the liver, we engineered mice carrying a fastinginducible NOS-2 transgene, which allows the synthesis of NO independently of inflammatory stimulation. Phenotypically, the expression of NOS-2 after the animals had fasted promoted a moderate change in the parameters related to oxidative stress, but this NO synthesis did not affect significantly the life-span, or it involved other systemic alterations of the normal behavior 
of the Tg animals with respect to the corresponding Wts. We analyzed other organs to determine the expression of the transgene and, except for minor expression in kidney tissue, it was not expressed in other organs including pancreas. These results suggest that moderate generation of $\mathrm{NO}$ at the hepatic level has no noticeable deleterious effects on liver. Indeed, it has been found that NOS-2 is expressed and functional in the trophoblasts after midterm pregnancy, and this NO seems not to affect other organs (50). However, in Tg animals carrying NOS-2 under the control of the insulin promoter, pancreatic cells expressed this enzyme, and the synthesis of NO provoked $\beta$-cell degeneration and the development of insulin-dependent diabetes (51).

Regarding our model, the data showed that administration of a high dose of LPS was lethal for both Wt and Tg animals, independently of their nutritional status. This lethality might be due to the insult exerted by LPS over other organs in addition to liver, likely including the renal and vascular systems. However, in D-GalN-conditioned mice, intrahepatic synthesis of NO protected against the lethal injury elicited by low doses of LPS, as deduced from the use of NOS-2 inhibitors, that suppressed the protection exerted by endogenous synthesis of NO in $\mathrm{Tg}$ animals and by the maintenance of liver function and structure under these conditions. Sensitization of animals with D-GalN enhanced the liver response to inflammatory factors, which allowed working with much lower concentrations of these molecules (36). Indeed, using high doses of LPS, Rouquet et al. (52) observed lethality in a model of inhibition of caspase activity with YVAD.CMK; however, complete protection by this inhibitor was obtained in the LPS/D-GalN model, suggesting an important contribution of liver apoptosis to the lethality induced by LPS in D-GalN conditioned mice $(26-28,45,53)$. In this regard, it is worthwhile to mention that, in transgenic animals overexpressing endothelial NOS, the enhanced NO synthesis protected the animals from LPS-induced septic shock. In this case, the mechanism by which endothelial NOS prevented LPS lethality involved $i$ ) attenuation of the expression of NOS-2, ii) impairment of vascular reactivity to $\mathrm{NO}$, and iii) inhibition of the expression of vascular cell adhesion molecule-1 (VCAM-1) and ICAM-1, concomitant with a reduction in the infiltration of leukocytes in various organs (54).

Analysis of the mechanisms mediating the protection exerted by hepatic NO synthesis included that of the inhibition of NF- $\mathrm{KB}$ activation, which was evidenced soon after LPS challenge and, therefore, was an impairment of the release of TNF- $\alpha$, IL-1 $\beta$, and presumably of other proinflammatory cytokines dependent on $\mathrm{NF}-\kappa \mathrm{B}$ activity $(2,17)$. The contribution of proinflammatory cytokines to lethality in the LPS/D-GalN model, in particular TNF- $\alpha$, has been well established since survival to LPS was observed in mice lacking TNF- $\alpha$ or the p55 receptor of TNF- $\alpha$ (47). Also, pretreatment of animals with a moderate nonlethal dose of LPS reduced the lethality of a further administration of LPS/D-GalN, including a reduction in the synthesis of TNF- $\alpha$ (55). Opposite to the protective effect by preexistent NO, the NO produced as a result of inflammatory expression of NOS-2 plays an important role in the pathogenesis of septic shock $(7,9)$. Indeed, induction of sepsis in mice deficient in NOS-2 resulted in a lower mortality than in the Wt counterparts, with a better evolution in the pharmacological management of hypotension with norepinephrine (56).

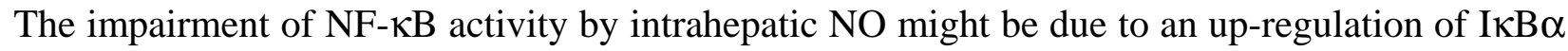
levels, a fact observed systematically in $\mathrm{Tg}$ animals that had fasted; to an inhibition of IкB phosphorylation (17), due to the inhibitory effect of NO on IאB kinase-2 activity (unpublished 
data); and to an inappropriate targeting of I $\kappa \mathrm{B}$ due to the inhibition of the proteasome activity by NO (57). Consistent with these suggestions are the data obtained using a "tet-off" transgenic system to express a degradation-resistant mutant of $\operatorname{I\kappa B} \alpha(20)$. These mutants demonstrate a regulated disruption of NF- $\kappa \mathrm{B}$ activity in postnatal liver tissue, but this disruption has no effect on the normal physiology of the organ; however, it severely impairs the ability to clear infection from the liver, indicating that NF- $\mathrm{KB}$ acts as an integrator of innate immunity in this organ. In addition to these effects of $\mathrm{NO}$ on I $\mathrm{KB}$ targeting, it has been described that pretreatment of cultured hepatocytes with NO donors protects against TNF- $\alpha$-dependent hepatotoxicity by upregulating heat shock protein 70 (hsp70) expression (53). Moreover, this increase of hsp70 appears to be dependent on an enhancement of GSSG concentration, a situation observed in fasted Tg animals.

An aspect partially explored in this work was the contribution of NO-dependent inhibition of procaspase activation and caspase activity to protection against liver inflammatory injury. NO inhibits the activities of liver caspases 3 and 8 through an $S$-nitrosylation mechanism, and they appear to be the most relevant executioner caspases in this organ $(49,58)$. The efficiency of this protective mechanism was confirmed using a model of adenovirus-mediated gene transfer of NOS-2 that abrogated the apoptosis dependent on TNF- $\alpha$ and actinomycin D (27). Moreover, in a model of concanavalin A-induced hepatitis, administration of chemical donors of NO improved survival through a mechanism that inhibited caspase-dependent processing of the Th1 response that mediates the coordinate apoptotic action of the cytokines released by $\mathrm{CD}^{+} \mathrm{T}$ cells and $\mathrm{T}$ helper cells. This caused Fas-dependent hepatocyte death (59). In our model, the amount of procaspase 3 was well conserved in Tg animals that had fasted after LPS/D-GalN challenge, and activation of caspase 3 (total activity because it was measured in the presence of dithiothreitol) was significantly lower than in the Wt group. In agreement with these results, minimal DNA laddering and TUNEL staining were observed in Tg animals when compared with that of their Wt counterparts.

Taken together these data suggest that the availability of a molecule delivering NO in the hepatocyte as result of hepatic metabolism might constitute a useful drug for the therapeutic management of various liver diseases.

\section{ACKNOWLEDGMENTS}

The authors thank Dr. F. Bosch, Dr. A. Valera, and Dr A. Pujol for help in the preparation of the Tg animals; Dr. José Rodrigo for help on the cytochemistry; and Dr. S. Lamas for critical reading of the manuscript. The technical help of Mari Carmen Tormos Muñoz and O. G. Bodelón are acknowledged. This work was supported by grants 98/0120, 2FD97-1432, and 08.3/0030/98 from Dirección General de Investigación Científica y Técnica, CICYT, and Comunidad de Madrid, respectively, and from Fundación Ramón Areces (X Concurso Nacional 1997).

\section{REFERENCES}

1. Fry, D. E. (2000) Sepsis syndrome. Am. Surg. 66, 126-132 
2. Karima, R., Matsumoto, S., Higashi, H., and Matsushima, K. (1999) The molecular pathogenesis of endotoxic shock and organ failure. Mol. Med. Today 5, 123-132

3. Issekutz, T. B. (1995) In vivo blood monocyte migration to acute inflammatory reactions, IL$1 \alpha$, TNF- $\alpha$, IFN- $\gamma$, and C5a utilizes LFA-1, Mac-1, and VLA-4. The relative importance of each integrin. J. Immunol. 154, 6533-6540

4. Baeuerle, P. A., and Baichwal, V. R. (1997) NF- $\kappa B$ as a frequent target for immunosuppressive and anti-inflammatory molecules. Adv. Immunol. 65, 111-137

5. Hickey, M. J., Sharkey, K. A., Sihota, E. G., Reinhardt, P. H., Macmicking, J. D., Nathan, C., and Kubes, P. (1997) Inducible nitric oxide synthase-deficient mice have enhanced leukocyte-endothelium interactions in endotoxemia. FASEB J. 11, 955-964

6. Dankesreiter, S., Hoess, A., Schneider-Mergener, J., Wagner, H., and Miethke, T. (2000) Synthetic endotoxin-binding peptides block endotoxin-triggered TNF- $\alpha$ production by macrophages in vitro and in vivo and prevent endotoxin-mediated toxic shock. J. Immunol. 164, 4804-4811

7. Hobbs, A. J., Higgs, A., and Moncada, S. (1999) Inhibition of nitric oxide synthase as a potential therapeutic target. Annu. Rev. Pharmacol. Toxicol. 39, 191-220

8. Hollenberg, S. M., Easington, C. R., Osman, J., Broussard, M., and Parrillo, J. E. (1999) Effects of nitric oxide synthase inhibition on microvascular reactivity in septic mice. Shock 12, 262-267

9. Wray, G. M., Millar, C. G., Hinds, C. J., and Thiemermann, C. (1998) Selective inhibition of the activity of inducible nitric oxide synthase prevents the circulatory failure, but not the organ injury/dysfunction, caused by endotoxin. Shock 9, 329-335

10. Fausto, N. (2000) Liver regeneration. J. Hepatol. 32, 19-31

11. Hortelano, S., Dewez, B., Genaro, A. M., Diaz-Guerra, M. J., and Bosca, L. (1995) Nitric oxide is released in regenerating liver after partial hepatectomy. Hepatology 21, 776-786

12. Curran, R. D., Billiar, T. R., Stuehr, D. J., Hofmann, K., and Simmons, R. L. (1989) Hepatocytes produce nitrogen oxides from L-arginine in response to inflammatory products of Kupffer cells. J. Exp. Med. 170, 1769-1774

13. Casado, M., Velasco, M., Bosca, L., and Martin-Sanz, P. (1997) Absence of NO synthase type II expression in fetal liver from pregnant rats under septic shock conditions. Hepatology 25, 1406-1411

14. Nussler, A. K., Beger, H. G., Liu, Z. Z., and Billiar, T. R. (1995) Nitric oxide, hepatocytes and inflammation. Res. Immunol. 146, 671-677

15. McCaughan, G. W., Gorrell, M. D., Bishop, G. A., Abbott, C. A., Shackel, N. A., McGuinness, P. H., Levy, M. T., Sharland, A. F., Bowen, D. G., Yu, D., Slaitini, L., Church, 
W. B., and Napoli, J. (2000) Molecular pathogenesis of liver disease: an approach to hepatic inflammation, cirrhosis and liver transplant tolerance. Immunol. Rev. 174, 172-191

16. Marra, F. (1999) Hepatic stellate cells and the regulation of liver inflammation. J. Hepatol. 31, 1120-1130

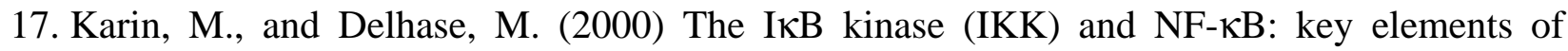
proinflammatory signalling. Semin. Immunol. 12, 85-98

18. Diaz-Guerra, M. J., Velasco, M., Martin-Sanz, P., and Bosca, L. (1997) Nuclear factor $\kappa B$ is required for the transcriptional control of type II NO synthase in regenerating liver. Biochem. J. 326, 791-797

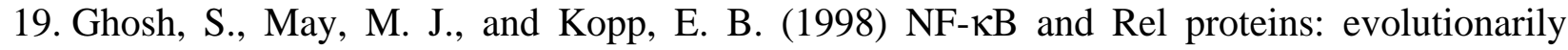
conserved mediators of immune responses. Annu. Rev. Immunol. 16, 225-260

20. Lavon, I., Goldberg, I., Amit, S., Landsman, L., Jung, S., Tsuberi, B. Z., Barshack, I., Kopolovic, J., Galun, E., Bujard, H., and Ben-Neriah, Y. (2000) High susceptibility to bacterial infection, but no liver dysfunction, in mice compromised for hepatocyte NF- $\mathrm{B}$ activation. Nat. Med. 6, 573-577

21. Taylor, B. S., Shao, L., Gambotto, A., Ganster, R. W., and Geller, D. A. (1999) Inhibition of cytokine-induced nitric oxide synthase expression by gene transfer of adenoviral I $\mathrm{BB} \alpha$. Surgery 126, 142-147

22. Kumins, N. H., Hunt, J., Gamelli, R. L., and Filkins, J. P. (1997) Molsidomine increases endotoxic survival and decreases cytokine production. Shock 7, 200-205

23. Park, J. H., Chang, S. H., Lee, K. M., and Shin, S. H. (1996) Protective effect of nitric oxide in an endotoxin-induced septic shock. Am. J. Surg. 171, 340-345

24. Pastor, C. M., Losser, M. R., and Payen, D. (1995) Nitric oxide donor prevents hepatic and systemic perfusion decrease induced by endotoxin in anesthetized rabbits. Hepatology 22, 1547-1553

25. Szabo, C., and Billiar, T. R. (1999) Novel roles of nitric oxide in hemorrhagic shock. Shock 12, 1-9

26. Kim, Y. M., Kim, T. H., Chung, H. T., Talanian, R. V., Yin, X. M., and Billiar, T. R. (2000) Nitric oxide prevents tumor necrosis factor $\alpha$-induced rat hepatocyte apoptosis by the interruption of mitochondrial apoptotic signaling through S-nitrosylation of caspase-8. Hepatology 32, 770-778

27. Tzeng, E., Billiar, T. R., Williams, D. L., Li, J., Lizonova, A., Kovesdi, I., and Kim, Y. M. (1998) Adenovirus-mediated inducible nitric oxide synthase gene transfer inhibits hepatocyte apoptosis. Surgery 124, 278-283 
28. Kim, Y. M., Talanian, R. V., and Billiar, T. R. (1997) Nitric oxide inhibits apoptosis by preventing increases in caspase-3-like activity via two distinct mechanisms. J. Biol. Chem. 272, 31138-31148

29. Morikawa, A., Kato, Y., Sugiyama, T., Koide, N., Chakravortty, D., Yoshida, T., and Yokochi, T. (1999) Role of nitric oxide in lipopolysaccharide-induced hepatic injury in Dgalactosamine-sensitized mice as an experimental endotoxic shock model. Infect. Immun. 67, $1018-1024$

30. Macmicking, J. D., Nathan, C., Hom, G., Chartrain, N., Fletcher, D. S., Trumbauer, M., Stevens, K., Xie, Q. W., Sokol, K., and Hutchinson, N. (1995) Altered responses to bacterial infection and endotoxic shock in mice lacking inducible nitric oxide synthase. Cell 81, 641650

31. Vodovotz, Y., Kopp, J. B., Takeguchi, H., Shrivastav, S., Coffin, D., Lucia, M. S., Mitchell, J. B., Webber, R., Letterio, J., Wink, D., and Roberts, A. B. (1998) Increased mortality, blunted production of nitric oxide, and increased production of TNF- $\alpha$ in endotoxemic TGF$\beta 1$ transgenic mice. J. Leukoc. Biol. 63, 31-39

32. Hierholzer, C., Harbrecht, B., Menezes, J. M., Kane, J., MacMicking, J., Nathan, C. F., Peitzman, A. B., Billiar, T. R., and Tweardy, D. J. (1998) Essential role of induced nitric oxide in the initiation of the inflammatory response after hemorrhagic shock. J. Exp. Med. 187, 917-928

33. Vos, T. A., Gouw, A. S., Klok, P. A., Havinga, R., van Goor, H., Huitema, S., Roelofsen, H., Kuipers, F., Jansen, P. L., and Moshage, H. (1997) Differential effects of nitric oxide synthase inhibitors on endotoxin-induced liver damage in rats. Gastroenterology 113, 13231333

34. Rai, R. M., Lee, F. Y., Rosen, A., Yang, S. Q., Lin, H. Z., Koteish, A., Liew, F. Y., Zaragoza, C., Lowenstein, C., and Diehl, A. M. (1998) Impaired liver regeneration in inducible nitric oxide synthase deficient mice. Proc. Natl. Acad. Sci. USA 95, 13829-13834

35. Miethke, T., Wahl, C., Heeg, K., Echtenacher, B., Krammer, P. H., and Wagner, H. (1992) T cell-mediated lethal shock triggered in mice by the superantigen staphylococcal enterotoxin B: critical role of tumor necrosis factor. J. Exp. Med. 175, 91-98

36. Galanos, C., Freudenberg, M. A., and Reutter, W. (1979) Galactosamine-induced sensitization to the lethal effects of endotoxin. Proc. Natl. Acad. Sci. USA 76, 5939-5943

37. Ferre, T., Pujol, A., Riu, E., Bosch, F., and Valera, A. (1996) Correction of diabetic alterations by glucokinase. Proc. Natl. Acad. Sci. USA 93, 7225-7230

38. Pelegrin, M., Devedjian, J. C., Costa, C., Visa, J., Solanes, G., Pujol, A., Asins, G., Valera, A., and Bosch, F. (1998) Evidence from transgenic mice that interferon- $\beta$ may be involved in the onset of diabetes mellitus. J. Biol. Chem. 273, 12332-12340 
39. Wong, S. H., Knight, J. A., Hopfer, S. M., Zaharia, O., Leach, C. N. J., and Sunderman, F. W. J. (1987) Lipoperoxides in plasma as measured by liquid-chromatographic separation of malondialdehyde-thiobarbituric acid adduct. Clin. Chem. 33, 214-220

40. Navarro, J., Obrador, E., Pellicer, J. A., Asensi, M., Vina, J., and Estrela, J. M. (1997) Blood glutathione as an index of radiation-induced oxidative stress in mice and humans. Free Radic. Biol. Med. 22, 1203-1209

41. Muniz, P., Valls, V., Perez-Broseta, C., Iradi, A., Climent, J. V., Oliva, M. R., and Saez, G. T. (1995) The role of 8-hydroxy-2'-deoxyguanosine in rifamycin-induced DNA damage. Free Radic. Biol. Med. 18, 747-755

42. McCord, J. M., and Fridovich, I. (1968) The reduction of cytochrome c by milk xanthine oxidase. J. Biol. Chem. 243, 5753-5760

43. Xie, Q. W., Whisnant, R., and Nathan, C. (1993) Promoter of the mouse gene encoding calcium-independent nitric oxide synthase confers inducibility by interferon $\gamma$ and bacterial lipopolysaccharide. J. Exp. Med. 177, 1779-1784

44. Velasco, M., Diaz-Guerra, M. J., Martin-Sanz, P., Alvarez, A., and Bosca, L. (1997) Rapid up-regulation of $\mathrm{I} \kappa \mathrm{B} \beta$ and abrogation of $\mathrm{NF}-\kappa \mathrm{B}$ activity in peritoneal macrophages stimulated with lipopolysaccharide. J. Biol. Chem. 272, 23025-23030

45. Martin-Sanz, P., Diaz-Guerra, M. J., Casado, M., and Bosca, L. (1996) Bacterial lipopolysaccharide antagonizes transforming growth factor $\beta 1$-induced apoptosis in primary cultures of hepatocytes. Hepatology 23, 1200-1207

46. Yamada, Y., Webber, E. M., Kirillova, I., Peschon, J. J., and Fausto, N. (1998) Analysis of liver regeneration in mice lacking type 1 or type 2 tumor necrosis factor receptor: requirement for type 1 but not type 2 receptor. Hepatology 28, 959-970

47. Nowak, M., Gaines, G. C., Rosenberg, J., Minter, R., Bahjat, F. R., Rectenwald, J., MacKay, S. L., Edwards, C. K., and Moldawer, L. L. (2000) LPS-induced liver injury in Dgalactosamine-sensitized mice requires secreted TNF- $\alpha$ and the TNF-p55 receptor. Am. J. Physiol. 278, R1202-R1209

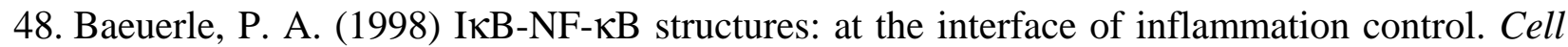
95, 729-731

49. Li, J., and Billiar, T. R. (1999) The anti-apoptotic actions of nitric oxide in hepatocytes. Cell Death Differ. 6, 952-955

50. Callejas, N. A., Casado, M., Bosca, L., and Martin-Sanz, P. (1999) Requirement of nuclear factor $\kappa \mathrm{B}$ for the constitutive expression of nitric oxide synthase- 2 and cyclooxygenase- 2 in rat trophoblasts. J. Cell Sci. 112, 3147-3155

51. Takamura, T., Kato, I., Kimura, N., Nakazawa, T., Yonekura, H., Takasawa, S., and Okamoto, H. (1998) Transgenic mice overexpressing type 2 nitric-oxide synthase in 
pancreatic $\beta$ cells develop insulin-dependent diabetes without insulitis. J. Biol. Chem. 273, 2493-2496

52. Rouquet, N., Pages, J. C., Molina, T., Briand, P., and Joulin, V. (1996) ICE inhibitor YVADcmk is a potent therapeutic agent against in vivo liver apoptosis. Curr. Biol. 6, 11921195

53. Kim, Y. M., de Vera, M. E., Watkins, S. C., and Billiar, T. R. (1997) Nitric oxide protects cultured rat hepatocytes from tumor necrosis factor- $\alpha$-induced apoptosis by inducing heat shock protein 70 expression. J. Biol. Chem. 272, 1402--1411

54. Yamashita, T., Kawashima, S., Ohashi, Y., Ozaki, M., Ueyama, T., Ishida, T., Inoue, N., Hirata, K., Akita, H., and Yokoyama, M. (2000) Resistance to endotoxin shock in transgenic mice overexpressing endothelial nitric oxide synthase. Circulation 101, 931-937

55. Endo, Y., Shibazaki, M., Yamaguchi, K., Kai, K., Sugawara, S., Takada, H., Kikuchi, H., and Kumagai, K. (1999) Enhancement by galactosamine of lipopolysaccharide (LPS)-induced tumour necrosis factor production and lethality: its suppression by LPS pretreatment. $B r . J$. Pharmacol. 128, 5-12

56. Hollenberg, S. M., Broussard, M., Osman, J., and Parrillo, J. E. (2000) Increased microvascular reactivity and improved mortality in septic mice lacking inducible nitric oxide synthase. Circ. Res. 86, 774-778

57. Glockzin, S., von Knethen, A., Scheffner, M., and Brune, B. (1999) Activation of the cell death program by nitric oxide involves inhibition of the proteasome. J. Biol. Chem. 274, 19581-19586

58. Li, J., Bombeck, C.A., Yang, S., Kim, Y. M., and Billiar, T. R. (1999) Nitric oxide suppresses apoptosis via interrupting caspase activation and mitochondrial dysfunction in cultured hepatocytes. J. Biol. Chem. 274, 17325-17333

59. Fiorucci, S., Santucci, L., Antonelli, E., Distrutti, E., Del Sero, G., Morelli, O., Romani, L., Federici, B., Del Soldato, P., and Morelli, A. (2000) NO-aspirin protects from T cellmediated liver injury by inhibiting caspase-dependent processing of Th1-like cytokines. Gastroenterology 118, 404-421 
Table 1

\begin{tabular}{|c|c|c|c|c|c|c|c|}
\hline \multicolumn{4}{|c|}{ i.p.challenge } & \multicolumn{2}{|c|}{ Fed } & \multicolumn{2}{|c|}{ Starved $(24 \mathrm{~h})$} \\
\hline $\begin{array}{l}\text { L-NIL } \\
(\mathrm{mg} / \mathrm{kg})\end{array}$ & $\begin{array}{l}\text { D-GalN } \\
(\mathrm{mg} / \mathrm{kg})\end{array}$ & $\begin{array}{c}\text { LPS } \\
(\mu \mathrm{g} / \mathrm{kg})\end{array}$ & $\begin{array}{l}\text { TNF- } \alpha \\
(\mu \mathrm{g} / \mathrm{kg})\end{array}$ & $\begin{array}{c}\mathrm{Wt} \\
\text { (survival/group) }\end{array}$ & $\begin{array}{c}\mathrm{Tg} \\
\text { (survival/group) }\end{array}$ & $\begin{array}{c}\mathrm{Wt} \\
\text { (survival/group) }\end{array}$ & $\begin{array}{c}\mathrm{Tg} \\
\text { (survival/group) }\end{array}$ \\
\hline- & - & 40,000 & - & $2 / 10$ & $1 / 10$ & $1 / 10$ & $0 / 10$ \\
\hline- & 800 & - & - & $5 / 5$ & $5 / 5$ & $6 / 6$ & $7 / 7$ \\
\hline- & - & 10 & - & $4 / 4$ & $4 / 4$ & $5 / 5$ & $5 / 5$ \\
\hline- & 800 & 10 & - & $2 / 8$ & $2 / 8$ & $0 / 12$ & $9 / 12$ \\
\hline 5 & 800 & 10 & - & $2 / 5$ & $1 / 5$ & $2 / 7$ & $1 / 7$ \\
\hline- & - & - & 20 & $5 / 5$ & $4 / 5$ & $4 / 5$ & $5 / 5$ \\
\hline- & 800 & - & 20 & $1 / 10$ & $0 / 10$ & $2 / 12$ & $8 / 12$ \\
\hline 5 & 800 & - & 20 & $1 / 5$ & $0 / 5$ & $0 / 6$ & $1 / 6$ \\
\hline
\end{tabular}

Table 1. Effect of LPS, TNF- $\alpha$, D-GalN, and the NOS-2 inhibitor L-NIL on animal survival. Animals aged 12-16 wk were i.p. injected $1 \mathrm{ml}$ of a mixture of the indicated stimuli in PBS. L-NIL was administered 30 min prior to proinflammatory treatment, and $8 \mathrm{~h}$ later. Starvation was carried out prior to challenge, and afterwards the animals had free access for food. The survival rates were determined $48 \mathrm{~h}$ after challenge. 
Fig. 1
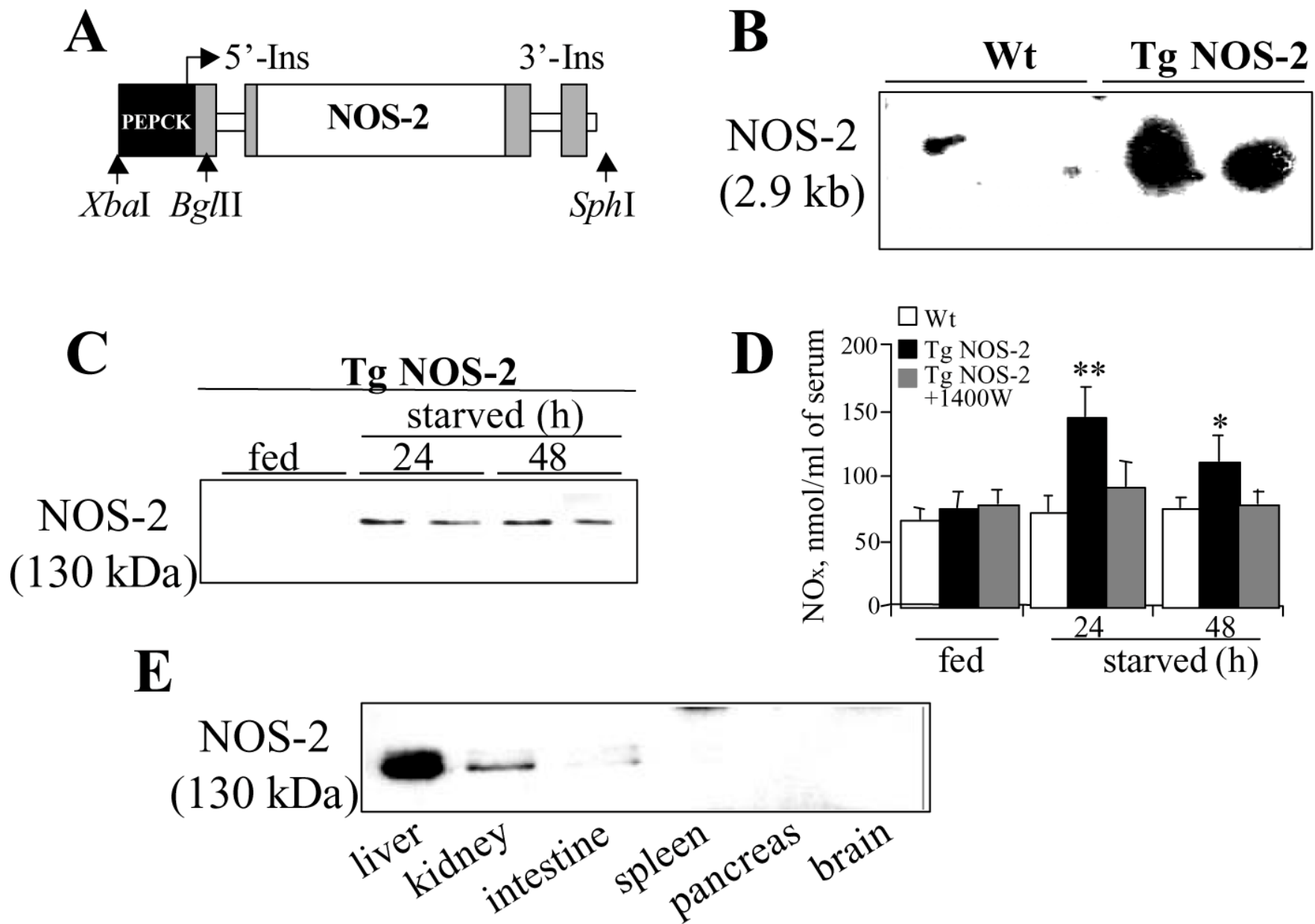

Figure 1. Analysis of the expression of the pPEPCK/NOS-2 transgene. The $6.2-\mathrm{kb}$ fragment containing the NOS-2 gene under the transcriptional control of the PEPCK promoter was microinjected into fertilized eggs (A). The presence of the chimeric transgene was determined by Southern blotting tail DNA (B). The expression of NOS-2 in Tg animals was determined at 0,24 , and $48 \mathrm{~h}$ of fasting by Western blotting liver extracts (C). In vivo expression and activity of NOS-2 was evaluated by measuring the accumulation of nitrate and nitrite in the serum by chemiluminiscence. Inhibition of NOS-2 activity in vivo with $1400 \mathrm{~W}$ (i.p. administration at $20 \mathrm{mg} / \mathrm{kg}$ ) was carried out twice per day (D). Analysis of NOS2 levels in different tissues was carried out by Western blot ( $20 \mu \mathrm{g}$ of protein) after $24 \mathrm{~h}$ of fasting. The blot was overexposed for the liver sample (E). Results show the blots of two animals per condition $(\mathbf{B}, \mathbf{C})$ the serum levels of NOx from four animals of each condition (mean $\pm \mathrm{SD}$; D), and a representative blot $(\mathbf{E}) .{ }^{*} P<0.5, * * P<0.01$ with respect to Wt animals under identical nutritional status. 
Fig. 2

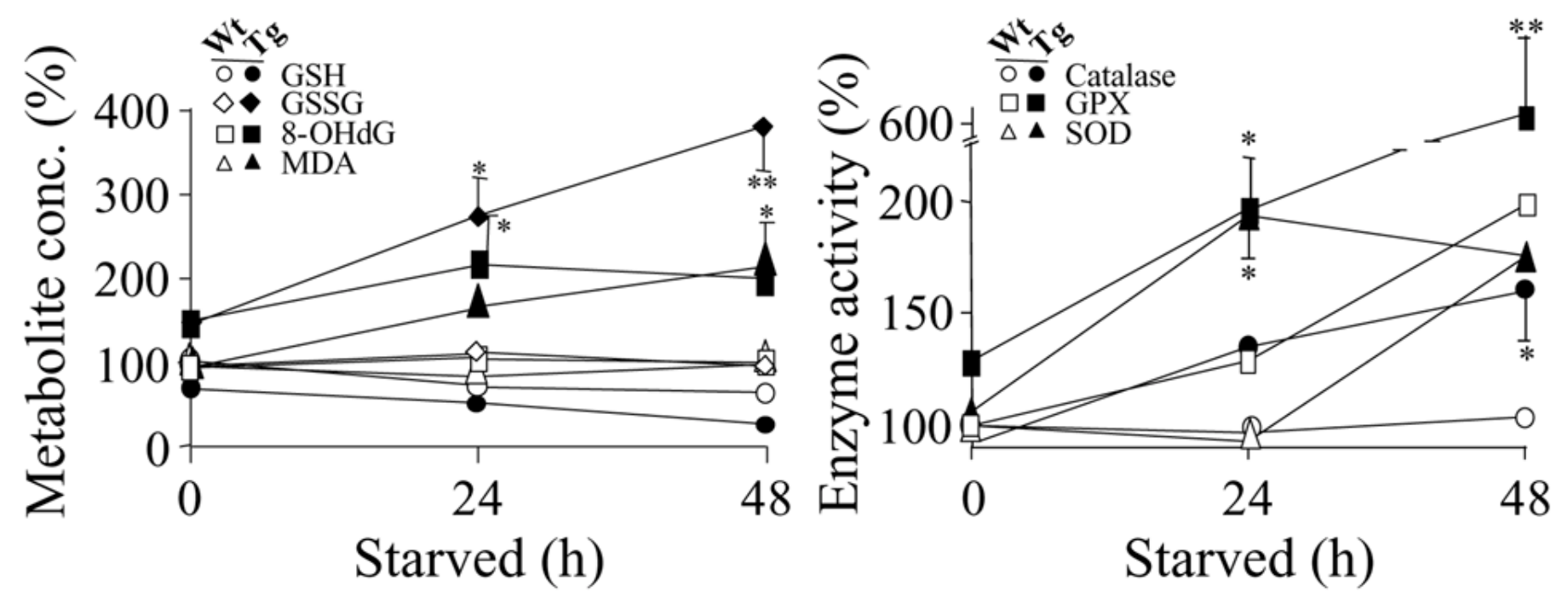

Figure 2. Metabolite concentrations and enzyme activities related to oxidative stress in Tg animals. Livers were removed at the indicated times and the concentrations of GSH, GSSG, MDA, and 8-OHdG were determined. The concentrations of these metabolites $($ mean $\pm \mathrm{SD}$ ) in Wt animals at $0 \mathrm{~h}$ were $1.73 \pm 0.52,0.42 \pm 0.19$, and $0.29 \pm 0.19$ $\mu \mathrm{mol} / \mathrm{g}$ of protein for GSH, GSSG, and MDA, and $2.6 \pm 0.85$ residues of 8 -OHdG per $10^{5}$ bases of dG ( $\left.n=7\right)$, respectively. The activity of catalase, GPX, and SOD was determined. The activities in Wt animals at $0 \mathrm{~h}$ were 40.2 $\pm 2.1,9.98 \pm 3.5$, and $16,000 \pm 427 \mathrm{U} / \mathrm{g}$ of protein $(n=6)$, respectively. Values were expressed in percentage, corresponding to the $100 \%$ value to $\mathrm{Wt}$ animals at $0 \mathrm{~h}$. $* P<0.5$, $* * P<0.01$ with respect to $\mathrm{Wt}$ animals under identical nutritional conditions. 
Fig. 3

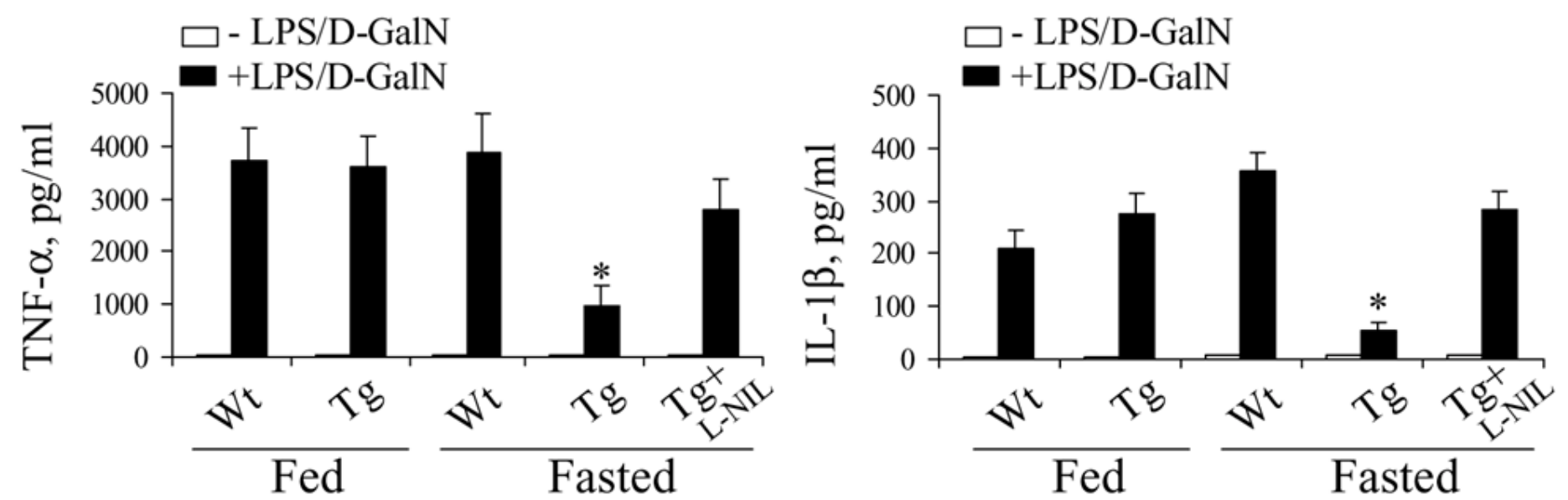

Figure 3. Impairment of the synthesis of pro-inflammatory cytokines in Tg animals expressing NOS-2. Fed and starved $(24 \mathrm{~h}) \mathrm{Wt}$ and Tg animals were challenged with i.p. injection of $1 \mathrm{ml}$ of LPS $(10 \mu \mathrm{g} / \mathrm{kg})$ and D-GalN $(800 \mathrm{mg} / \mathrm{kg})$ dissolved in saline. L-NIL ( $5 \mathrm{mg} / \mathrm{kg}$ ) was administered $30 \mathrm{~min}$ prior to challenge. The serum levels of TNF- $\alpha$ and IL-1 $\beta$ were determined after $4 \mathrm{~h}$ of challenge. Results show the mean \pm SD of three experiments $(n=4) . * P<0.001$ with respect to Wt animals under identical nutritional conditions. 
Fig. 4
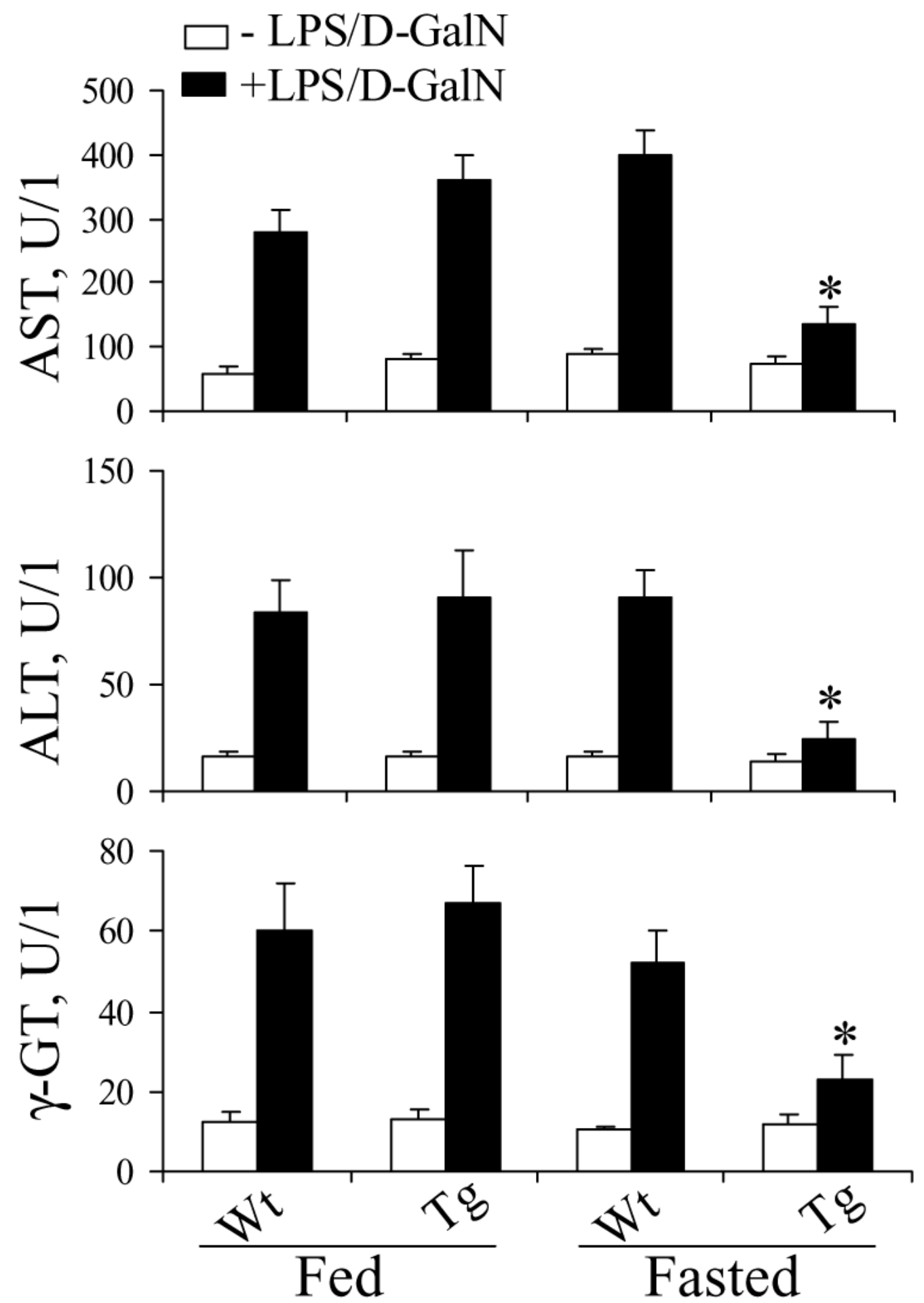

Figure 4. Protection by NO against LPS/D-GalN-induced liver injury. Animals were treated as indicated in Figure 3, and the activity of aspartate and alanine aminotransferases and $\gamma$-glutamyltransferase (AST, ALT, and $\gamma$ GT, respectively) was measured in serum $5 \mathrm{~h}$ after challenge. ${ }^{*} P<0.005$ with respect to $\mathrm{Wt}$ animals under identical nutritional conditions. 
Fig. 5
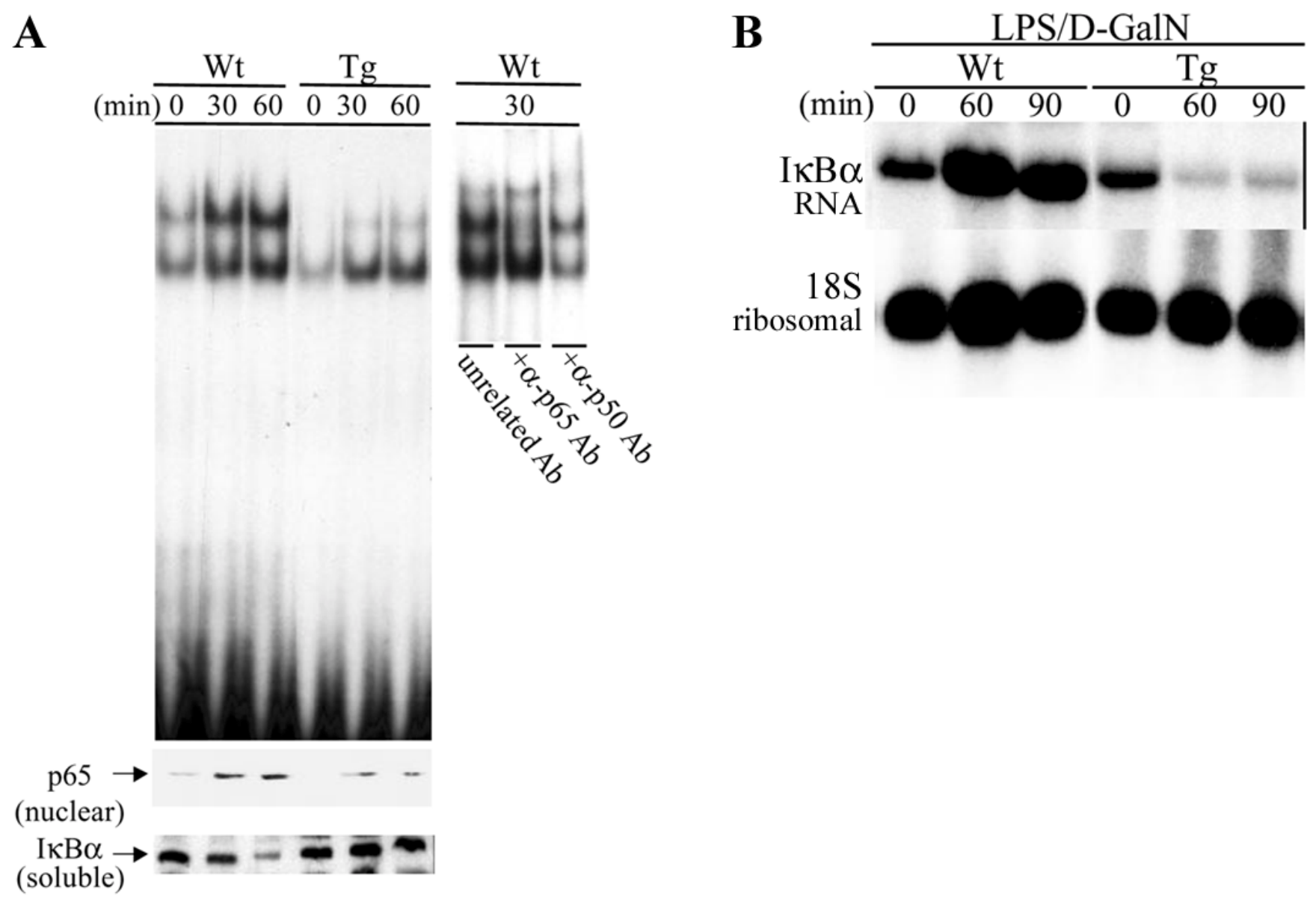

Figure 5. Inhibition of NF-kB activity in Tg animals expressing NOS-2. Fasted animals were treated with LPS/D-GalN, and at the indicated times the livers were removed and processed to prepare soluble and nuclear protein extracts. The binding of nuclear proteins to the proximal $\kappa B$ motif of the murine NOS-2 promoter was analyzed by EMSA. Supershift assays were carried out with the Wt samples at $30 \mathrm{~min}$. The levels of p65 (nuclear) and IkB $\alpha$ (cytosolic) were determined by Western blot (left panel). The levels of I $\kappa \mathrm{B} \alpha \mathrm{mRNA}$ were determined by Northern blot in liver samples obtained at the indicated times (right panel). The amount of $18 \mathrm{~S}$ ribosomal RNA was used to normalize the lane charge of RNA. Results show a representative experiment out of four. 
Fig. 6
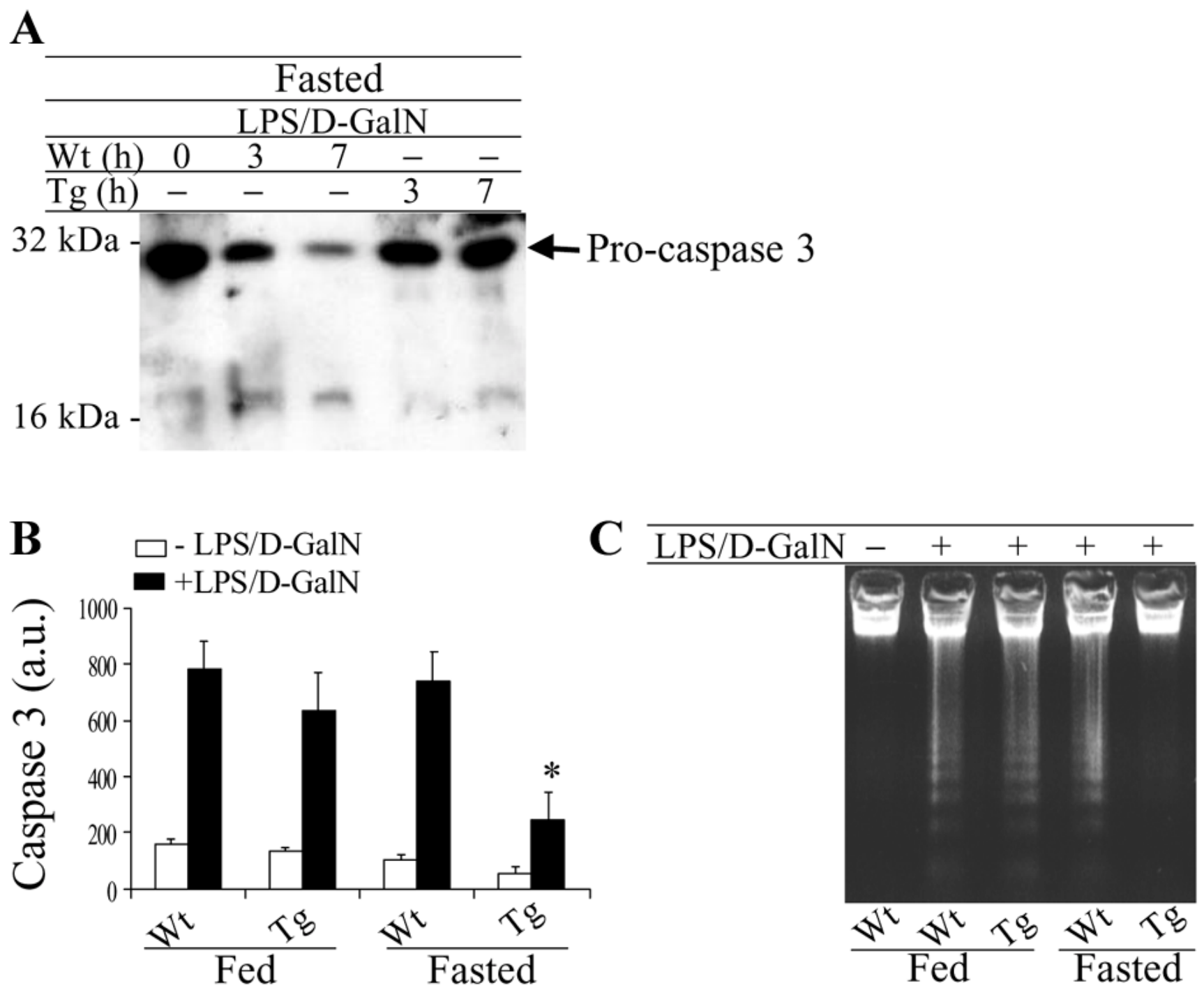

Figure 6. Protection by endogenous NO against LPS/D-GalN-induced apoptosis. Animals were treated as described in Figure 3. Livers were removed at the indicated times, and tissue extracts were prepared. Samples of soluble fraction were analyzed by Western blot by using an anti-caspase-3 Ab (A). The caspase activity was assayed at $5 \mathrm{~h}$ after LPS/D-GalN challenge by using the methylcoumarin conjugate of DEVD (caspase 3) as substrate. As a control of the specificity of the reaction, the basal activity corresponding to samples incubated with the corresponding peptide aldehydes was subtracted (B). The DNA obtained from animals treated for $7 \mathrm{~h}$ with LPS/D-GalN was analyzed by electrophoresis in agarose gels (C). Results show a representative experiment out of three $(\mathbf{A}, \mathbf{C})$, and the mean \pm SD of four experiments $(\mathbf{B})$. $* P<0.005$ with respect to the corresponding Wt group. 
Fig. 7



Figure 7. TUNEL assay and cytochemistry of liver sections from fasted Wt and Tg animals. Livers from control and animals treated $7 \mathrm{~h}$ with LPS/D-GalN animals and with or without L-NIL ( $5 \mathrm{mg} / \mathrm{kg}$ ) were obtained and fixed in $2 \%$ paraformaldehyde in phosphate buffer. Sections of $8 \mu \mathrm{m}$ were used for TUNEL following the instructions of the supplier (Roche); original magnification, $\times 630$. Staining with hematoxylin and eosin was carried out with samples of challenged animals at $7 \mathrm{~h}$; original magnification, $\times 200$. 